under standard conditions, with a mean concentration of $0.126 \times 10^{6}$ cells $/ \mathrm{mL}$ and $97.9 \%( \pm 1.7 \%)$ viability. Injection velocity ranged from 1.01 to $73.17 \mathrm{cc} / \mathrm{min}$, with no significant difference in cell count or viability. The same result was seen in either tortuous or straight microcatheter configurations. Cell count and viability did not change significantly when the hMSC in solution was stored for up to 5 hours on ice or mixed with Omnipaque, verapamil, and heparin. Notably, antiglioma activity was maintained after microcatheter infusion.

Conclusions BM-hMSCs are compatible with a wide variety of commonly used neuroendovascular microcatheters and medications. Stem cell viability and viral agent activity do not appear to be affected by catheter configuration or injection velocity. Commercially available microcatheters can be used to deliver IA stem cell neurotherapeutics.

Disclosures V. Srinivasan: None. J. Gumin: None. K. Camstra: None. S. Chen: None. J. Johnson: None. F. Lang: None. P. Kan: 2; C; Stryker, Medtronic, Cerenovus.

\section{0-033 POST-EMBOLIZATION CONTRASTED MRI ENHANCEMENT OF MENINGIOMAS IS A GREATER PREDICTOR OF INTRAOPERATIVE BLOOD LOSS THAN ANGIOGRAPHY}

J Catapano*, C Pryzbylowski, A See, A Whiting, M Labib, N Rubel, V Fredrickson, A Ducruet, F Albuquerque, N Sanai. Neurosurgery, Barrow Neurological Institute, Phoenix, $A Z$

\subsection{6/neurintsurg-2019-SNIS.33}

Objective Pre-operative embolization of meningiomas remains controversial. Prior studies have shown that the degree of devascularization on angiography is not significantly correlated with intraoperative blood loss. This study examines pre and post-embolization MRI enhancement as an improved metric for assessing the degree of embolization.

Methods We retrospectively analyzed patients who underwent preoperative embolization for intracranial meningiomas at the Barrow Neurological Institute from 2007 to 2017. Two cohorts were analyzed based on the degree of devascularization observed $(>/=50 \%$ vs. $<50 \%)$.

Results 84 meningioma patients underwent preoperative embolization. 35 (42\%) had post-embolization MR imaging prior to surgical resection. The mean lesion diameter was 4.9 $\mathrm{cm}( \pm 1.3)$ and, intraoperatively, the mean blood loss was $576 \mathrm{ml}( \pm 341)$. Based on MR imaging, angiography overestimated devascularization in 22 patients (63\%). 17 (49\%) patients were found to have a $>/=50 \%$ decrease enhancement on contrasted post-embolization MRI which was associated with lower mean intraoperative blood loss [444 $\mathrm{ml}$ vs. $700 \mathrm{ml}$ in 17 patients with $<50 \%$ devascularization $(\mathrm{p}=0.025)]$. On angiography, 22(63\%) patients demonstrated $>/=50 \%$ devascularization during embolization. These patients did not statistically differ in intraoperative blood loss as compared to those with $<50 \%$ devascularization on angiography. On univariate analysis, patients with $<50 \%$ decrease in enhancement on contrasted post-embolization MRI had 9 times greater odds of having at least $500 \mathrm{cc}$ of intraoperative blood loss during resection (CI 1.6-54, $\mathrm{p}=0.012$ ). Additionally, on multivariate stepwise logistic regression analysis $<50 \%$ decrease enhancement on contrasted post-embolization MRI was found to be a predictor of at least $500 \mathrm{cc}$ of blood loss (OR 9.4, p =0.012), but $<50 \%$ devascularization on angiography was not.
Conclusion Post-embolization contrasted MRI is a better predictor of intraoperative blood loss during meningioma resection than post-embolization angiography, which overestimates the degree of devascularization.

Disclosures J. Catapano: None. C. Pryzbylowski: None. A. See: None. A. Whiting: None. M. Labib: None. N. Rubel: None. V. Fredrickson: None. A. Ducruet: None. F. Albuquerque: None. N. Sanai: None.

\section{0-034 THROMBECTOMY FOR ACUTE ISCHEMIC STROKE IN NONAGENARIANS COMPARED TO OCTOGENARIANS}

${ }^{1}$ E Sussman*, ${ }^{2} B$ Martin, ${ }^{3} \mathrm{M}$ Mlynash, ${ }^{2} \mathrm{M}$ Marks, ${ }^{2} \mathrm{D}$ Marcellus, ${ }^{3} \mathrm{G}$ Albers, ${ }^{3} \mathrm{M}$ Lansberg, ${ }^{1} \mathrm{R}$ Dodd, ${ }^{2} \mathrm{H}$ Do, ${ }^{2} \mathrm{~J}$ Heit. ${ }^{1}$ Neurosurgery, Stanford University, Stanford, $C A$; ${ }^{2}$ Radiology, Stanford University, Stanford, $C A ;{ }^{3}$ Neurology, Stanford University, Stanford, $C A$

\subsection{6/neurintsurg-2019-SNIS.34}

Introduction Recent landmark randomized clinical trials have demonstrated that endovascular thrombectomy (EVT) leads to improved outcomes in patients with acute ischemic stroke (AIS) due to large vessel occlusion (LVO). Although elderly patients were excluded from several of these initial trials, the available data suggests a benefit of EVT in octogenarian patients with AIS due to LVO. However, the efficacy of EVT in the nonagenarian patient population remains uncertain.

Methods We performed a retrospective cohort study of a prospectively-maintained stroke database at a single comprehensive stroke center. Inclusion criteria were: age 80-99 years, LVO, core infarct $<70 \mathrm{~mL}$ on perfusion imaging, and presence of a salvageable penumbra. Patients were stratified based on age into octogenarian (age 80-89) and nonagenarian (age 90-99) cohorts. Primary outcome was ordinal score on the modified Rankin Scale (mRS) at 90 days. Secondary outcomes included dichotomized functional outcome (mRS $\leq 2$ versus $m R S \geq 3$ ), successful revascularization, symptomatic reperfusion hemorrhage and mortality.

Results 108 patients met inclusion criteria, including 79 octogenarians (73\%) and 29 nonagenarians (27\%). Mean octogenarian age was 84.2 years (SD 2.8) versus 92 years (SD 2.3) in nonagenarians. Nonagenarians were more likely to be female $(86 \%$ versus $58 \%$; $<<0.01)$; there were no other differences between the groups in terms of demographics, medical comorbidities, pre-treatment clinical variables, or endovascular treatment characteristics. Median mRS at 90 days was 5 (IQR 3-6) in octogenarians and 6 (IQR 4-6) in nonagenarians $(p=0.09)$. Independent functional status $(m R S \leq 2)$ at 90 days was achieved in $13 \%$ of nonagenarians and in $20 \%$ of octogenarians $(p=0.54)$. Successful revascularization (TICI 2b-3) was achieved in $79 \%$ in both the octogenarian and nonagenarian cohorts $(p=1)$. Symptomatic reperfusion hemorrhage occurred in $21 \%$ of nonagenarians and in $6 \%$ of octogenarians $(p=0.03)$. The 90 -day mortality rate was $63 \%$ in nonagenarians versus $41 \%$ in octogenarians $(p=0.07)$.

Conclusions Nonagenarian patients undergoing EVT for AIS due to LVO are at significantly higher risk of symptomatic reperfusion hemorrhage compared with octogenarians, despite similar stroke- and treatment-related factors. While there was a strong trend towards higher mortality rates and worse longterm functional outcomes in nonagenarians, the difference was not statistically significant in this relatively small retrospective study. Additional prospective and randomized studies are necessary to evaluate the efficacy of EVT in elderly patients, including nonagenarians. 
Disclosures E. Sussman: None. B. Martin: None. M. Mlynash: None. M. Marks: None. D. Marcellus: None. G. Albers: None. M. Lansberg: None. R. Dodd: None. H. Do: None. J. Heit: None.

\section{0-035 IGNORE THE CORE: DOES RECENT ADMINISTRATION OF INTRAVENOUS IODINATED CONTRAST RENDER CORE INFARCT ESTIMATION INACCURATE UTILIZING THE AUTOMATED CT PERFUSION RAPID SOFTWARE?}

${ }^{1} \mathrm{~A}$ Copelan*, ${ }^{1} \mathrm{G}$ Drocton, ${ }^{2} \mathrm{E}$ Smith, ${ }^{1} \mathrm{R}$ Khangura, ${ }^{1} \mathrm{D}$ Murph, ${ }^{1} \mathrm{C}$ Dowd, ${ }^{1} \mathrm{~V}$ Halbach, ${ }^{1} \mathrm{R}$ Higashida, ${ }^{1} \mathrm{~S}$ Hetts, ${ }^{1} \mathrm{D}$ Cooke, ${ }^{1} \mathrm{M}$ Amans. ${ }^{1}$ Neurointerventional Radiology, University of California San Francisco, San Francisco, CA; ${ }^{2}$ Department of Radiology, Medical College of Wisconsin, Milwaukee, WI

\subsection{6/neurintsurg-2019-SNIS.35}

Background and Purpose Automated computed tomography perfusion (CTP) software is increasingly utilized to aid in treatment decisions in emergent large vessel occlusion (ELVO), particularly in extended window stroke patients. Neurointerventionalists must be cognizant of pitfalls of these software packages in predicting ischemic core and penumbra. This study aims to assess whether RAPID post-processing software underestimates core infarct in patients who have recently received intravenous iodinated contrast, a common scenario in stroke transfer patients who undergo CTA at an outside hospital to confirm ELVO prior to transfer.

Methods We retrospectively reviewed 271 consecutive patients at our institution who underwent CTA \pm CTP for symptoms of acute ischemic stroke (AIS) from May 2018 through January 2019. Patient exclusion was predominantly on the basis of lack of anterior circulation ELVO on CTA or lack of performance of CTP with RAPID post-processing. Two blinded raters independently assessed CT Alberta Stroke Program Early Computed Tomography Score (ASPECTS) on the non-enhanced head CT (NECT) at the time of CTP and also collected clinical as well imaging data, including time from last known well (LKW) to CTP, collaterals grade, and core infarct $(\mathrm{mL})$ as predicted by RAPID software. Patients were dichotomized into those who received recent intravenous contrast (within 12 hours of CTP) and contrast naïve patients. Correlation between ASPECTS and core infarct $(\mathrm{mL})$ on RAPID software were analyzed for the two cohorts.

Results A total of 48 patients with a mean age of 74.1 years (SD 16.4) were included. The two cohorts comprised 24 patients each. There were baseline differences in mean ASPECTS (8.5 vs 5.6, p<0.001) and time from LKN to CTP acquisition (469 mins vs 740 mins, $p<0.001$ ) in the contrast naïve and prior contrast groups, respectively. However, when adjusting for these variables on multivariate regression analysis, there is a statistically significant difference in core infarct per RAPID, with underestimation of core infarct in those patients who received recent contrast $(p=0.016)$. In addition, there was a stronger correlation between ASPECTS and core infarct per RAPID in the contrast naïve patients $(\mathrm{r}=-0.745)$ compared to those who received recent contrast $(r=-0.42)$.

Conclusion Patients that previously received contrast had a much higher likelihood of underestimation of ischemic core using RAPID than contrast naïve patients. Those involved in the care of ELVO patients should avoid overreliance on RAPID post-processing for treatment disposition, particularly if the patient has received recent intravenous contrast.

Disclosures A. Copelan: None. G. Drocton: None. E. Smith: None. R. Khangura: None. D. Murph: None. C. Dowd: None. V. Halbach: None. R. Higashida: None. S. Hetts: None. D. Cooke: None. M. Amans: None.

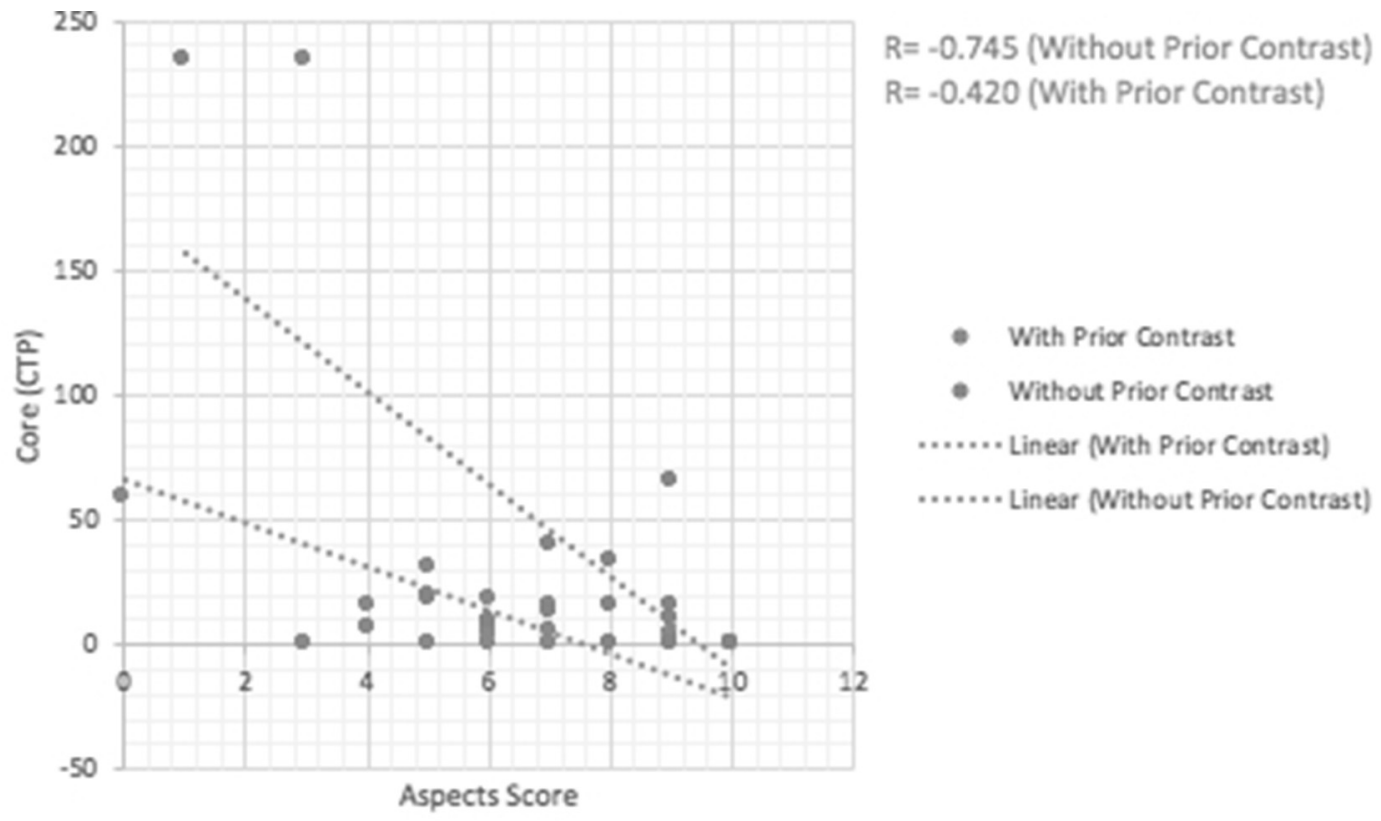

Abstract 0-035 Figure 1 